\title{
Weight loss medications in Canada - a new frontier or a repeat of past mistakes?
}

\author{
Sean Wharton ${ }^{1,2}$ \\ Jasmine Lee' \\ Rebecca AG Christensen' \\ 'The Wharton Medical Clinic, \\ Hamilton, ON, Canada; ${ }^{2}$ School of \\ Kinesiology and Health Science, York \\ University, Toronto, ON, Canada
}

This article was published in the following Dove Press journal: Diabetes, Metabolic Syndrome and Obesity:Targets and Therapy 4 October 2017

Number of times this article has been viewed

Correspondence: Sean Wharton The Wharton Medical Clinic, Weight and Diabetes Management, 295I

Walkers Line, Main Floor, Burlington, ON L7M 4YI, Canada

$\mathrm{Tel}+\mathrm{I} 905592230 \mathrm{I}$

$\mathrm{Fax}+\mathrm{I} 9055922302$

Email wharton.sean@gmail.com
Abstract: Current methods for the treatment of excess weight can involve healthy behavior changes, pharmacotherapy, and surgical interventions. Many individuals are able to lose some degree of weight through behavioral changes; however, they are often unable to maintain their weight loss long-term. This is in part due to physiological processes that cannot be addressed through behavioral changes alone. Bariatric surgery, which is the most successful treatment for excess weight to date, does result in physiological changes that can help with weight loss and weight maintenance. However, many patients either do not qualify or elect to not have this procedure. Fortunately, research has recently identified changes in neurochemicals (i.e., orexigens and anorexigens) that occur during weight loss and contribute to weight regain. The neurochemicals and hormones may be able to be targeted by medications to achieve greater and more sustained weight loss. Two medications are approved in adjunction to lifestyle management for weight loss in Canada: orlistat and liraglutide. Both medications are able to target physiological processes to help patients lose weight and maintain a greater amount of weight loss than with just behavioral modifications alone. Two other weight management medications, which also target specific physiological processes to aid in weight loss and its maintenance, a bupropion/naltrexone combination and lorcaserin, are currently pending approval in Canada. Nonetheless, there remain significant barriers for health care professionals to prescribe medications for weight loss, such as a lack of training and knowledge in the area of obesity. Until this has been addressed, and we begin treating obesity as we do other diseases, we are unlikely to combat the increasing trend of obesity in Canada and worldwide.

Keywords: weight loss, pharmacological intervention, liraglutide, weight loss medication

\section{Introduction}

In Canada, an estimated 4.3 million adults fit the criteria for obesity (body mass index $[\mathrm{BMI}] \geq 30 \mathrm{~kg} / \mathrm{m}^{2}$ ), with rates predicted to rise in all provinces until 2019 . ${ }^{1}$ These numbers reflect the elusiveness of effective obesity prevention and therapy. As excess weight is associated with an increased mortality ${ }^{2}$ and risk of developing comorbidities, ${ }^{3,4}$ effective intervention is needed. Available treatments for excess weight can be broken down into three categories: behavioral modifications, medications, and surgical interventions. As behavioral modifications have variable success rates, ${ }^{5,6}$ and many patients eligible for bariatric surgery elect to not have surgery, ${ }^{7,8}$ medications may be a way to bridge the gap and provide effective treatment for weight management. 


\section{Treatment options for excess weight}

Behavioral modification, which can be comprised of physical activity, caloric restriction, or both, is the cornerstone of weight management. Results of several meta-analyses suggest that physical activity interventions, without calorie restriction are associated with significantly lower reductions in weight than dietary alone, or combined interventions. ${ }^{6,9,10}$ Due to the differences in these behavioral modifications, there is considerable variability in the amount of weight loss achieved (range: $2 \%-13 \%$ of initial body weight loss). ${ }^{5,6}$ While this suggests that some patients are able to achieve reductions in weight using these methods, those who participate in behavioral modifications appear to be poor at maintaining the weight loss long-term. ${ }^{6,11,12}$ Weight regain, often referred to as weight cycling or yo-yo dieting, is a cyclical pattern which can increase the risk of developing cardiovascular disease or type 2 diabetes. ${ }^{13}$

Bariatric surgery, which has proven to be the most successful treatment for obesity, has until recently been reserved only for those in the highest BMI. While some medical centers are beginning to offer bariatric surgery to treat comorbidities in patients who are overweight or mildly obese,${ }^{14}$ current clinical guidelines in Canada still recommend bariatric surgery only for individuals with a BMI $\geq 40 \mathrm{~kg} / \mathrm{m}^{2}$, or a BMI $\geq 35 \mathrm{~kg} / \mathrm{m}^{2}$ with an obesity related comorbidity, such as type 2 diabetes or hypertension. ${ }^{15}$ Bariatric surgery is a relatively safe procedure with a low chance of mortality (range: $0.11 \%$ $0.34 \%$ ) or complications (range: $1.44 \%-5.91 \%$ ) following surgery. ${ }^{16}$ Further, individuals who have bariatric surgery can have complete reversal of their comorbidity(ies). ${ }^{16}$ Nonetheless, due to incorrect perceptions of risk, more than half of eligible patients state that they are not interested in bariatric surgery ${ }^{7,8}$ This begs the question of whether there is a solution for others, specifically patients living with obesity who do not want or do not qualify for surgery.

Pharmacotherapy is currently approved as an adjunct to lifestyle interventions for weight management in patients with a BMI $\geq 30 \mathrm{~kg} / \mathrm{m}^{2}$ or a BMI $\geq 27 \mathrm{~kg} / \mathrm{m}^{2}$ with at least one obesity related comorbidity. ${ }^{15}$ Prior to 2010 , attempts to introduce effective, evidenced-based pharmacotherapy for weight management were ridden with significant adverse effects, often cardiac in nature, resulting in sweeping withdrawals from the market. ${ }^{17,18}$ However, recent findings within obesity research suggest that medications may play an important role in combating physiological processes that prevent patients from losing weight or cause patients to gain back the weight that they have already lost.

\section{Current research on the mechanisms of weight loss and weight maintenance}

During weight loss, the production of weight gaining neurochemicals (orexigens) increases. ${ }^{19}$ Orexigens, such as ghrelin, induce hunger, lower metabolism and promote cravings for calorie-dense foods. ${ }^{19}$ Simultaneously, weight losing neurochemicals (anorexigens), decrease during weight loss which promotes weight regain and the maintenance of patients' heaviest weight. ${ }^{20}$ This highlights the importance of choosing a course of treatment which addresses physiological responses to weight loss or weight regain may be imminent. Bariatric surgery, despite its invasive nature, has been shown to successfully boost anorexigens and dampens the release of orexigens. ${ }^{21}$ Consequently, it has been argued that a primary mechanism of weight loss due to surgery relates to neurochemical modulation rather than simply mechanical restriction or malabsorption. ${ }^{22,23}$ While this modality is unlikely a scalable option due to cost and expertise requirements, pharmacotherapy may be a more accessible means of large-scale treatment.

Obesity is a complex and multifactorial disease that develops from the interaction of metabolic, genetic, social, behavioral and cultural factors. Consequently, a collection of diverse medications designed around the biology of weight changes must be developed and approved for improved treatment. Where science had previously failed to develop safe and reliable weight management medications, likely owing to the limited body of evidence surrounding weight mechanisms, research has progressed rapidly over the past 20 years. ${ }^{18,24}$ This has revealed hormones, neurochemicals and microbiomes that are directly related to weight changes, ${ }^{18,24}$ which pharmaceutical agents may be able to target to aid patients in not only losing weight but also maintaining their weight loss.

\section{Pharmacotherapy for obesity}

Currently, options for the pharmacological treatment of obesity remain limited. While some medications (i.e., buproprion/naltrexone combination and lorcaserin) await approval for weight management in Canada, two medications have been approved as a treatment option - orlistat and liraglutide.

Orlistat, which was approved by Health Canada in 1999, is currently recommended for weight reduction and maintenance in conjunction to lifestyle management. ${ }^{25}$ Patients are instructed to take $120 \mathrm{mg}$ during or up to 1 hour after meals, 3 times per day. ${ }^{25}$ Several meta-analyses which 
evaluated the efficacy of orlistat observed that patients taking orlistat lost 2.7 to $2.9 \mathrm{~kg}$ more than controls. ${ }^{26-28}$ Patients who continued to take orlistat also appeared to maintain a greater amount of weight loss. A study by Sjöström et $\mathrm{al}^{29}$ observed that when patients consumed a weight maintenance diet, those taking orlistat regained less weight than those who discontinued orlistat and those who remained on the placebo.

While orlistat does not target neurochemical and hormonal alterations, it aids patients in reducing their weight by blocking lipase activity which prevents approximately $30 \%$ of dietary fat from being broken down into free fatty acids. ${ }^{30}$ Thus, rather than dietary fat being absorbed in the intestines it is excreted in feces. The mechanisms of action for orlistat likely contribute to its side-effects which are primarily gastro-intestinal in nature and include oily stools and fecal incontinence. ${ }^{25}$ These side-effects can result in the discontinuation of orlistat, with the results of a meta-analysis suggesting that patients prescribed orlistat are 1.59 times more likely to withdraw from the intervention than those taking the placebo. ${ }^{31}$

The newest addition to pharmacological weight loss medications in Canada, liraglutide $3 \mathrm{mg}$, was approved for use in August 2015. ${ }^{32}$ As the prescription of liraglutide as a weight management therapy is relatively new, there are no meta-analyses that examine the efficacy of this medication at its clinical dose of $3 \mathrm{mg}$. Nonetheless, several large scale randomized control trials (RCTs) have demonstrated the efficacy of liraglutide $3 \mathrm{mg}$ as an adjunct to lifestyle for weight management with patients losing 4.2 to $5.9 \mathrm{~kg}$ more than those taking the placebo. ${ }^{33-36}$ Similar to orlistat, it appears that patients must continue taking liraglutide to maintain their weight loss. One study observed that patients who discontinued liraglutide for 12 weeks regained more weight $(2.9 \%)$ than patients who continued taking $(0.7 \%)$, or never took the medication $(0.3 \%) .{ }^{35}$ Further, Astrup et $\mathrm{al}^{33}$ directly compared weight loss outcomes on liraglutide and orlistat, and observed that individuals taking liraglutide lost on average $3.0 \mathrm{~kg}$ more than those prescribed orlistat. This greater weight loss observed in patients taking liraglutide may in part be due to its mechanism of action. Liraglutide is a glugcagon-like peptide-1 (GLP-1) receptor stimulator. GLP-1, which is naturally secreted by the body when glucose or fat is ingested, binds to receptors in the hypothalamus resulting in the suppression of appetite ${ }^{37}$ and a reduction in gastric emptying. ${ }^{38}$ Thus, unlike orlistat which just prevents the absorption of food once consumed, liraglutide works to prevent patients from even consuming these calories in the first place.
Reports of side-effects from RCTs suggest patients taking liraglutide tend to experience side-effects that are gastro-intestinal in nature, such as nausea and vomiting. ${ }^{33-35}$ However, these side-effects tend to be transient in nature and can be mitigated by a slow dose titration. ${ }^{39}$ When directly comparing rates of side-effects in patients taking liraglutide and orlistat, Astrup et $\mathrm{al}^{39}$ observed that those taking liraglutide experienced more minor (94.6\%) and severe $(1.0 \%)$ adverse events than those taking orlistat (minor: $85.3 \%$, severe: $0.0 \%$ ). While a greater proportion of patients taking liraglutide withdrew from the trial due to side-effects (liraglutide: $5.4 \%$ versus orlistat: $3.2 \%$ ) the overall withdrawal rate in the trial was greater in those taking orlistat (liraglutide: $12 \%$ versus orlistat: $17 \%) .{ }^{39}$

Liraglutide appears to be associated with greater improvements in metabolic health than orlistat in the only study to compare the two drugs head to head. Following a 20 week RCT where patients were randomized to receive liraglutide, orlistat, or placebo, patients taking liraglutide had greater improvements in fasting glucose, and hemoglobin A1c. ${ }^{39}$ The liraglutide group also had a greater reduction in the prevalence of metabolic syndrome and prediabetes at follow-up than those randomized to orlistat.

\section{Emerging anti-obesity medications in Canada}

Currently, there are two other weight management medications that are approved for use in the US and are pending approval with Health Canada: a bupropion/naltrexone combination and lorcaserin. Bupropion and naltrexone are currently approved in Canada as a monotherapy for depression/smoking cessation, ${ }^{40}$ and the treatment of opioid/alcohol dependence, ${ }^{41}$ respectively. The combination medication is thought to decrease weight by stimulating the release of anorexic hormones from the hypothalamus while simultaneous inhibiting the release of hormones which would counteract these effects. ${ }^{42}$ Lorcaserin, which is a selective serotonin receptor agonist, is also thought to activate receptors in the hypothalamus, which results in increased satiety. ${ }^{43}$

Several RCTs have examined the efficacy of these medications for weight management and suggest that both of these agents are associated with significantly greater weight loss than taking a placebo ${ }^{44}{ }^{47}$ The results of the phase 3 clinical trials indicate that the bupropion/naltrexone combination results in a $8.1 \%$ total weight $\operatorname{loss}^{45}$ and $5.8 \%$ total weight loss for lorcaserin. ${ }^{46}$ While adverse events were reported for both medications, these side-effects were generally considered minor and were not associated with patients discontinuing the intervention. ${ }^{45,46}$ 


\section{Barriers to the prescription of medications for weight management}

As we cautiously yet optimistically embark on a new horizon of obesity treatment, additional reforms in the framework of obesity medicine and research are warranted. First, it has become clear that the majority of health care professionals (HCPs) lack the resources and/or knowledge to provide meaningful and adequate obesity treatment to their patients. ${ }^{48}$ Lack of appropriate training, and significant adverse effects of previously failed or withdrawn anti-obesity drugs may result in HCPs being reluctant to prescribe medications for treatment. HCPs must be receptive to supplementary training on obesity science and stay current with the latest findings in obesity research. Organizations such as the American Board of Obesity Medicine and the Canadian Obesity Network are available resources to cater to these needs.

In recognition of the Canadian Medical Association's designation of obesity as a disease, individual HCPs should follow through on acknowledging obesity in the same manner as other chronic diseases by embracing effective treatments, such as surgery and pharmacotherapy. Further, research advancements on patients living with obesity should be conducted to target populations who will respond most favorably to a certain obesity medication. Essentially, we have to be open to a new and diverse generation of safe and effective anti-obesity medications that cater to different predictors of obesity to provide the highest quality of care available. Finally, long-term research and surveillance is necessary to assess the durability of these medications, and to detect potential adverse effects.

\section{Conclusion}

Rates of obesity continue to increase within Canada and abroad, yet there remains insufficient prevention and treatment options. Behavioral modification, which is the cornerstone of weight management, has had limited success when used on its own. While bariatric surgery remains the most effective treatment for obesity, it is not scalable and is considered risky and too invasive by many patients and HCPs. Thus, the need for effective and low risk pharmacological treatments is paramount. Currently, Canada has approved orlistat and liraglutide $3 \mathrm{mg}$ for weight management, with two more medications awaiting approval. It is time for HCPs, patients, and all stakeholders to learn from recent scientific and clinical findings in obesity research, and start using pharmacotherapy appropriately. By avoiding the evidence, it will ensure we continue to remain in the dark.

\section{Acknowledgement}

The authors would like to thank Nicole Bhoop for her support with the edits.

\section{Author contributions}

All authors contributed toward data analysis, drafting and revising the paper and agree to be accountable for all aspects of the work.

\section{Disclosure}

This research did not receive any specific grant from funding agencies in the public, commercial, or not-for-profit sectors. SW is the Medical Director at Wharton Medical Clinic and an Internal Medicine specialist at Toronto East General Hospital and Hamilton Health Sciences Center. SW has received funding in the past from MITACs, CIHR and is currently an advisory board member for Eli Lilly, Novo Nordisk, Astra Zeneca, Merck, Sanofi, Canadian Diabetes Association, and the Canadian Obesity Network. RAGC is the Research Coordinator at the Wharton Medical Clinic. JL reports no conflicts of interest in this work.

\section{References}

1. Twells LK, Gregory DM, Reddigan J, Midodzi WK. Current and predicted prevalence of obesity in Canada: a trend analysis. CMAJ Open. 2014;2(1):E18-26.

2. Flegal KM, Kit BK, Orpana H, Graubard BI. Association of all-cause mortality with overweight and obesity using standard body mass index categories: a systematic review and meta-analysis. JAMA. 2013;309(1):71-82.

3. Must A, Spadano J, Coakley EH, Field AE, Colditz G, Dietz WH. The disease burden associated with overweight and obesity. JAMA. 1999;282(16):1523-1529.

4. De Pergola G, Silvestris F. Obesity as a major risk factor for cancer. J Obes. 2013;2013:291546.

5. Dakour Aridi HN, Wehbe MR, Shamseddine G, Alami RS, Safadi BY. Long-term outcomes of Roux-en-Y gastric bypass conversion of failed laparoscopic gastric band. Obes Surg. 2017;27(6):1401-1408.

6. Curioni CC, Lourenço PM. Long-term weight loss after diet and exercise: a systematic review. Int J Obes (Lond). 2005;29(10):1168-1174.

7. Fung M, Wharton S, Macpherson A, Kuk JL. Receptivity to bariatric surgery in qualified patients. J Obes. 2016;2016:5372190.

8. Wharton S, Serodio KJ, Kuk JL, SIvapalan N, Craik A, Aarts MA. Interest, views and perceived barriers to bariatric surgery in patients with morbid obesity. Clin Obes. 2016;6(2):154-160.

9. Johns DJ, Hartmann-Boyce J, Jebb SA, Aveyard P. Diet or exercise interventions vs combined behavioral weight management programs: a systematic review and meta-analysis of direct comparisons. J Acad Nutr Diet. 2014;114(10):1557-1568.

10. Miller WC, Koceja DM, Hamilton EJ. A meta-analysis of the past 25 years of weight loss research using diet, exercise or diet plus exercise intervention. Int J Obes. 1997;21(10):941-947.

11. Brownell KD, Jeffery RW. Improving long-term weight loss: pushing the limits of treatment. Behav Ther. 1987;18(4):353-374.

12. Jeffery RW, Drewnowski A, Epstein LH, et al. Long-term maintenance of weight loss: current status. Health Psychol. 2000;19(1S):5-16.

13. Strohacker K, Carpenter KC, McFarlin BK. Consequences of weight cycling: an increase in disease risk? Int J Exerc Sci. 2009;2(3):191-201. 
14. Mayo Clinic Staff. Bariatric surgery - Mayo Clinic. (2016). Available from: http://www.mayoclinic.org/tests-procedures/bariatric-surgery/ basics/why-its-done/prc-20019138. Accessed June 25, 2017.

15. Lau DC, Douketis JD, Morrison KM, Hramiak IM, Sharma AM, Ur E. 2006 Canadian clinical practice guidelines on the management and prevention of obesity in adults and children [summary]. CMAJ. 2007;176(8):S1-13.

16. Hutter MM, Schirmer BD, Jones DB, et al. First report from the American College of Surgeons Bariatric Surgery Center Network: laparoscopic sleeve gastrectomy has morbidity and effectiveness positioned between the band and the bypass. Ann Surg. 2011:254(3):410-422.

17. Rodgers RJ, Tschöp MH, Wilding JP. Anti-obesity drugs: past, present and future. Dis Model Mech. 2012;5(5):621-626.

18. Dietrich MO, Horvath TL. Limitations in anti-obesity drug development: the critical role of hunger-promoting neurons. Nat Rev Drug Discov. 2012;11(9):675-691.

19. Hansen TK, Dall R, Hosoda H, et al. Weight loss increases circulating levels of ghrelin in human obesity. Clin Endocrinol (Oxf). 2002;56(2):203-206

20. Schmidt JB, Gregersen NT, Pedersen SD. Effects of PYY3-36 and GLP-1 on energy intake, energy expenditure, and appetite in overweight men. Am J Physiol Endocrinol Metab. 2014;306(11):E1248-56.

21. Park CW, Torquati A. Physiology of weight loss surgery. Surg Clin North Am. 2011;91(6):1149-qq61, vii.

22. Ionut V, Bergman RN. Mechanisms responsible for excess weight loss after bariatric surgery. J Diabetes Sci Technol. 2011;5(5):1263-1282.

23. Arble DM, Sandoval DA, Seeley RJ. Mechanisms underlying weight loss and metabolic improvements in rodent models of bariatric surgery. Diabetologia. 2015;58(2):211-220.

24. Suzuki K, Jayasena CN, Bloom SR. Obesity and appetite control. Exp Diabetes Res. 2012;2012:824305.

25. Roche. Xenical Product Monograph. (2015). Available from: http:// www.rochecanada.com/content/dam/roche_canada/en_CA/documents/ Research/ClinicalTrialsForms/Products/ConsumerInformation/MonographsandPublicAdvisories/Xenical/Xenical_PM_E.pdf. Accessed April 3, 2017.

26. Rucker D, Padwal R, Li SK, Curioni C, Lau DC. Long term pharmacotherapy for obesity and overweight: updated meta-analysis. $B M J$. 2007;335(7631):1194-1199.

27. Li Z, Maglione M, Tu W, et al. Meta-analysis: pharmacologic treatment of obesity. Ann Intern Med. 2005;142(7):532-546.

28. Padwal R, Li SK, Lau DC. Long-term pharmacotherapy for overweight and obesity: a systematic review and meta-analysis of randomized controlled trials. Int J Obes Relat Metab Disord. 2003;27(12):1437-1446.

29. Sjöström L, Rissanen A, Andersen T, et al. Randomised placebo-controlled trial of orlistat for weight loss and prevention of weight regain in obese patients. European Multicentre Orlistat Study Group. Lancet. 1998;352(9123):167-172.

30. McNeely W, Benfield P. Orlistat. Drugs. 1998;56(2):241-249; discussion 250

31. Johansson K, Neovius K, DeSantis SM, Rössner S, Neovius M. Discontinuation due to adverse events in randomized trials of orlistat, sibutramine and rimonabant: a meta-analysis. Obes Rev. 2009;10(5): $564-575$.
32. Novo Nordisk. Saxenda Product Monograph. (2016). Available from: http://www.novonordisk.ca/content/dam/Canada/AFFILIATE/wwwnovonordisk-ca/OurProducts/PDF/Saxenda_PM_English.pdf, Accessed April 3, 2017.

33. Astrup A, Carraro R, Finer N, et al. Safety, tolerability and sustained weight loss over 2 years with the once-daily human GLP-1 analog, liraglutide. Int J Obes (Lond). 2012;36(6):843-854.

34. Davies MJ, Bergenstal R, Bode B, et al. Efficacy of liraglutide for weight loss among patients with type 2 diabetes: the SCALE diabetes randomized clinical trial. JAMA. 2015;314(7):687-699.

35. Pi-Sunyer X, Astrup A, Fujioka K, et al. A randomized, controlled trial of $3.0 \mathrm{mg}$ of liraglutide in weight management. $N$ Engl J Med. 2015;373(1):11-22.

36. Wadden TA, Hollander P, Klein S, et al. Weight maintenance and additional weight loss with liraglutide after low-calorie-diet-induced weight loss: The SCALE Maintenance randomized study. Int J Obes (Lond). 2013;37(11):1443-1451.

37. Woods SC, D'Alessio DA. Central control of body weight and appetite. J Clin Endocrinol Metab. 2008;93(11 Suppl 1):S37-S50.

38. Delgado-Aros S, Kim DY, Burton DD, et al. Effect of GLP-1 on gastric volume, emptying, maximum volume ingested, and postprandial symptoms in humans. Am J Physiol Gastrointest Liver Physiol. 2002;282(3):G424-431.

39. Astrup A, Rössner S, Van Gaal L, et al. Effects of liraglutide in the treatment of obesity: a randomised, double-blind, placebo-controlled study. Lancet. 2009;375(9701):1606-1616.

40. Mucklow JC. Martindale: the complete drug reference. $\mathrm{Br} J \mathrm{Clin}$ Pharmacol. 2000;49(6):613.

41. Apotex. Revia Monograph. (2003). Available from: http://shoppershealthcare-portal-a88a1f4b.s3.amazonaws.com/AgilityUGC/bd7cfe4da0ae-4496-a4e4-f2ebdbaf6f5d/EN_PM00003584.PDF. Accessed June 25, 2017.

42. Ornellas T, Chavez B. Naltrexone SR/Bupropion SR (Contrave): a new approach to weight loss in obese adults. $P$ T. 2011;36(5):255-262.

43. Thomsen WJ, Grottick AJ, Menzaghi F, et al. Lorcaserin, a novel selective human 5-hydroxytryptamine $2 \mathrm{C}$ agonist: in vitro and in vivo pharmacological characterization. J Pharmacol Exp Ther. 2008;325(2):577-587.

44. Wadden TA, Foreyt JP, Foster GD, et al. Weight loss with naltrexone SR/ bupropion SR combination therapy as an adjunct to behavior modification: the COR-BMOD trial. Obesity. 2011;19(1):110-120.

45. Greenway FL, Fujioka K, Plodkowski RA, et al. Effect of naltrexone plus bupropion on weight loss in overweight and obese adults (COR-I): a multicentre, randomised, double-blind, placebo-controlled, phase 3 trial. Lancet. 2010;376(9741):595-605.

46. Smith SR, Weissman NJ, Anderson CM, et al. Multicenter, placebocontrolled trial of lorcaserin for weight management. $N$ Engl J Med. 2010;363(3):245-256.

47. O'Neil PM, Smith SR, Weissman NJ, et al. Randomized placebocontrolled clinical trial of lorcaserin for weight loss in type 2 diabetes mellitus: the BLOOM-DM study. Obesity (Silver Spring). 2012;20(7):1426-1436.

48. Bleich SN, Bennett WL, Gudzune KA, Cooper LA. National survey of US primary care physicians' perspectives about causes of obesity and solutions to improve care. BMJ Open. 2012;2:e001871.

Diabetes, Metabolic Syndrome and Obesity: Targets and Therapy

\section{Publish your work in this journal}

Diabetes, Metabolic Syndrome and Obesity: Targets and Therapy is an international, peer-reviewed open-access journal committed to the rapid publication of the latest laboratory and clinical findings in the fields of diabetes, metabolic syndrome and obesity research. Original research, review, case reports, hypothesis formation, expert opinion and commentaries are all considered for publication. The manuscript management system is completely online and includes a very quick and fair peer-review system, which is all easy to use. Visit http://www.dovepress.com/testimonials.php to read real quotes from published authors. 